\title{
REFLEXÕES SOBRE RESPONSABILIDADE SOCIAL EMPRESARIAL
}

\author{
Gisele Dayane Milani ${ }^{1}$, Tassiany Maressa Santos Aguiar ${ }^{2}$ \\ ${ }^{1}$ Pontifícia Universidade Católica de São Paulo - PUC, Doutoranda em Serviço Social, São Paulo, SP. Bolsista CAPES. \\ ${ }^{2}$ Centro Universitário Toledo, curso de Ciências Contábeis, Presidente Prudente, SP. E-mail: giselemilani@hotmail.com
}

\section{RESUMO}

Este artigo tem por objetivo apresentar reflexões críticas sobre a Responsabilidade Social Empresarial na contemporaneidade, enquanto estratégia de gestão norteada por valores de sustentabilidade, assim como destacar seu marco histórico, conceituação e atuação do Instituto Ethos de Responsabilidade Social Empresarial- referência no campo de estudo. Trata-se de uma pesquisa em que foram realizadas pesquisa bibliográfica, pesquisa documental em fontes secundárias e a pesquisa de campo nas organizações associadas ao Instituto Ethos de Responsabilidade Social. Como resultados, apresentamos que para a Responsabilidade Social se efetive com excelência na prática das organizações, precisa estar atrelada a um processo de gestão (diagnostico, planejamento, execução, monitoramento e avaliação) pautados em princípios éticos e de sustentabilidade, cuja direção não é apenas o hoje, mas os impactos futuros de suas ações.

Palavras-chave: Negócios. Sustentabilidade. Responsabilidade Social Empresarial. Gestão. Ethos.

\section{REFLECTIONS ON CORPORATE SOCIAL RESPONSIBILITY}

\section{ABSTRACT}

This article aims to present critical reflections about Corporate Social Responsibility in the contemporary world, as a management strategy guided by sustainability values, as well its historical, conceptualization and performance of the Ethos Institute for Corporate Social Responsibility in the field of study. It is a research with bibliographical research, documentary research in secondary sources and field research were carried out in organizations associated to the Ethos Institute of Social Responsibility. As a result, we present that for Social Responsibility to be effective with excellence in the practice of organizations, it must be linked to a management process (diagnosis, planning, execution, monitoring and evaluation) based on ethical principles and sustainability, whose direction is not only today, but the future impacts of its actions.

Keywords: Sustainability. Corporate Social Responsibility. Management. Ethos

\section{CONSIDERAÇÕES INICIAIS}

As considerações aqui apresentadas, foram construídas no processo de reflexão e síntese durante a elaboração da dissertação de mestrado (de ambas) sobre Responsabilidade Social Empresarial- RSE e Investimento Social Privado. Objetivo é de publicizar as reflexões tecidas ao longo de dois anos de pesquisa sobre Responsabilidade Social, destacar seu marco histórico, conceituação, e atuação do Instituto Ethos.

Esta é uma pesquisa qualitativa a fim de identificar e analisar a dimensão da responsabilidade social empresarial. Conforme Martinelli (2005, p. 119), "[...] a finalidade última da pesquisa qualitativa é conhecer a experiência do grupo pesquisado e os significados que atribuem a tal experiência. Para o equacionamento da pesquisa, foram realizadas: pesquisa bibliográfica, pesquisa documental em fontes secundárias e a pesquisa de campo nas organizações associadas ao Instituto Ethos de Responsabilidade Social. 
Neste contexto, cabe destacar que, é sob a égide do capitalismo, na sociedade de produção, que surge a responsabilidade social empresarial. Proveniente de determinado estágio da gestão empresarial, essa nova forma integra valores éticos como norteadores de negócios e requer o pensamento em estratégias e políticas que envolvam uma relação socialmente responsável por parte das empresas, tornando-as agentes e parceiras de uma sociedade mais sustentável. Além disso, tal forma deve envolver o público com o qual se relaciona, os stakeholders ${ }^{1}$.

Segundo Fischer (2002, pp. 74-75), no início do século XX correntes de pensamento buscaram ampliar a relação da empresa com o ambiente social, ressaltando a importância da interação das organizações com o sistema social do qual faziam parte. Conforme a autora,

Desta reflexão surge o conceito de responsabilidade social empresarial ou corporativa, que é cunhado, no âmbito da teoria das organizações, como uma das funções organizacionais a serem administradas, no fluxo das relações e interações, que se estabelecem entre os sistemas empresariais específicos e o sistema social mais amplo (FISCHER, 2002, p. 75).

De início, afirma Fischer, o conceito não foi absorvido. As empresas explicitavam a intenção de aderir ao cumprimento de sua função social, mas na prática se limitavam a ações pontuais e esporádicas. Seria, pois, cenário complexo da mundialização econômica que tornaria, de todo modo, propício o ressurgimento do exercício da Responsabilidade Social.

Em síntese, as empresas competem entre si de forma acirrada e pressões como a citada mundialização econômica, a intensificação da inovação tecnológica, consumidores cada vez mais exigentes, fazem parte de um cenário em que apenas a qualidade e o preço não são mais tão atrativos como outrora. A sobrevivência e o sucesso da corporação empresarial passaram também a requerer a adoção de práticas que tragam um diferencial, que conquistem a preferência dos consumidores.

FISCHER (2002, p. 44), mais uma vez, ajuda a compreender esse processo, o qual se relaciona ao contexto histórico já apresentado:

As crises econômicas abalaram a economia do país, a confiança dos investidores externos, a segurança e auto-estima dos empresários nacionais. Nos anos noventa, o movimento de globalização da economia pressionou o Brasil a adotar políticas liberalizantes e a enfrentar os desafios da modernização. A indústria local sucumbiu à competição acirrada e à perda das medidas protecionistas do Estado. Crise fiscal, abertura às importações, privatizações e intensificação da entrada de capital internacional transformaram, radicalmente, o cenário da economia brasileira na passagem do século sem, contudo, promover a erradicação dos desequilíbrios econômicos e sociais que agravam cada vez mais a vida dos brasileiros.

No amplo cenário acima destacado, as parcerias entre Estado, Mercado e Sociedade Civil adquirem uma importante dimensão, mesmo até necessária no esforço de se promover o desenvolvimento sustentável.

De acordo com Alessio (2003, p. 04), em meados da década de 1960 a Reponsabilidade Social já estava em uso nos Estados Unidos, mas só foi incorporada no Brasil à medida em que os empresários notaram as vantagens que tal prática poderia trazer para os negócios. Ela se

\footnotetext{
1 Segundo Machado Filho (2006, p. 03), "stakeholders" se refere a todos os públicos com os quais a empresa se relaciona, a saber: funcionários, consumidores, acionistas, fornecedores, prestadores de serviço, comunidade, governo etc.

Colloquium Socialis, Presidente Prudente, v. 01, n. Especial 2, Jul/Dez, 2017, p.827-832. DOI: 10.5747/cs.2017.v01.nesp2.s0235
} 
intensificou a partir da década de 1990 no contexto do processo de redemocratização, de abertura econômica e de incentivo à Reforma do Estado no Brasil, que, por sua vez, esteve atrelada aos interesses das novas configurações das relações internacionais em meio à crise global do sistema capitalista e do neoliberalismo. As empresas começaram, por exemplo, a desenvolver políticas de preservação do meio ambiente e a se sensibilizar com iniciativas de apoio a ações de cunho social.

Assim, recorda-nos ALESSIO (2008, pp. 100-101),

[...] o movimento da responsabilidade social das empresas, cuja projeção nos EUA e na Europa aconteceu em meados da década de 60, passou a ser pauta na agenda dos empresários brasileiros, com mais visibilidade, na década de 90, incentivado pelo período de redemocratização e abertura econômica do País, pelos direitos conquistados com a Constituição Federal de 1988, pela aprovação do Estatuto da Criança e do Adolescente (ECA) e do Código de Proteção e Defesa do Consumidor, em 1990, pela aprovação da Lei Orgânica da Assistência Social (LOAS), em 1992, que contribuíram para uma maior conscientização e organização da sociedade civil sobre seus direitos, também favorecendo a fundação de ONGs e o fortalecimento do Terceiro Setor.

A ideia de responsabilidade social, desse modo, ganhou projeção no meio empresarial brasileiro apenas nos anos de 1990. Segundo GRAYSON E HODGES (2012, p. 74), "numa economia global interconectada, os consumidores (que hoje são em geral mais bem informados e mais afluentes do que nunca) serão fiéis a marcas e organizações que lhes deem razões para confiar". De acordo com o autor, para garantir contratos e negócios, também é importante que as companhias demonstrem determinado envolvimento com o meio ambiente e com a comunidade.

Neste sentido, PAES (2003, p. 25) afirma que:

Diante dessa nova organização empresarial global, as organizações privadas possuem uma nova diretriz nos rumos da obtenção do lucro, pois simplesmente as vantagens oferecidas em relação a valores (preços) não estão sendo suficientes para a obtenção de um mercado consumidor. Cada vez mais a qualidade do produto está relacionada à relação da empresa com a sociedade e seu comportamento ético e esses fatores determinam o comportamento dos consumidores.

Nota-se que a responsabilidade social empresarial surge no momento em que o papel das empresas também é questionado e sofre transformações. É interessante acrescentar que as atividades predatórias oriundas da intensa fabricação de novos produtos começaram a gerar insatisfação por parte da sociedade e reconheceu-se, desde então, que o consumo possuía implicações sociais. Do exposto, pode-se afirmar que a notoriedade da responsabilidade social se deu também devido à deterioração dos ecossistemas na sociedade industrial.

Assim, a sobrevivência das empresas também depende de satisfação das partes envolvidas. Entendemos que as relações entre a sociedade e as organizações são dialéticas, o que significa dizer que a sociedade interfere na existência da empresa e que, como as empresas fazem parte da sociedade, elas também sofrem alterações.

\section{MÉTODO}

Trata-se de um assunto relevante e que pode ser de interesse de pesquisadores e profissionais. Contribuímos, assim, para a interação e o crescimento da produção sobre uma temática atual e desafiadora. 
Fruto da pesquisa realizada por ambas as autoras para a elaboração da dissertação de mestrado em Serviço Social - objeto de estudo - Responsabilidade Social Empresarial e Investimento Social Privado. Equacionado neste artigo, através de considerações e reflexões críticas obtidas através das pesquisas bibliográficas realizadas, pesquisa documental em fontes secundárias e pesquisa junto às organizações associadas ao Instituto Ethos de Responsabilidade Social do Estado de São Paulo, órgão de referência na temática.

\section{RESULTADO}

O foco de trabalho do Instituto ETHOS ${ }^{2}$, destarte, será a Responsabilidade Social. Segundo o ETHOS (2007, p. 04), uma série de instituições adotaram o conceito de responsabilidade social empresarial, como a Corporate Social Responsibility - CSR-Europe, o Sustainability Institute, Business for Social Responsibility - BSR, a International Finance Corporation - IFC, o Institute of Social and Ethical Accoun-tability, o Instituto ETHOS de Empresas e Responsabilidade Social etc. Tal conceito é definido

[...] pela relação que a empresa estabelece com todos os seus públicos (stakeholders) no curto e no longo prazo. Os públicos de relacionamento da empresa envolvem inúmeras organizações de interesse civil/social/ambiental, além daqueles usualmente reconhecidos pelos gestores - público interno, acionistas e consumidores/clientes. (ETHOS, 2007, p. 4).

É, ainda, organizado em sete tópicos: "valores, transparência e governança; público interno; meio ambiente; fornecedores; consumidores/clientes; comunidade; governo e sociedade" (ETHOS, 2007, p. 04). Segundo o ETHOS, a responsabilidade social pode ser compreendida, assim, como um modelo de gestão empresarial, de condução dos negócios com foco na gestão, a ser levado por qualquer empresa, utilizando-se recursos privados para fins públicos.

Nesse sentido, temos ainda o conceito da ABNT NBR ISO $26000^{3}$ :

Segundo a ISO 26000, a responsabilidade social se expressa pelo desejo e pelo propósito das organizações em incorporarem considerações socioambientais em seus processos decisórios e a responsabilizar-se pelos impactos de suas decisões e atividades na sociedade e no meio ambiente. Isso implica um comportamento ético e transparente que contribua para o desenvolvimento sustentável, que esteja em conformidade com as leis aplicáveis e seja consistente com as normas internacionais de comportamento. Também implica que a responsabilidade social esteja integrada em toda a organização, seja praticada em suas relações e leve em conta os interesses das partes interessadas.

Os dois conceitos, dessa maneira, abordam a responsabilidade social como modelo de gestão corporativa e denota uma postura pautada em valores éticos na condução das ações organizacionais, capaz de integrar o público com o qual a empresa se relaciona.

A Responsabilidade Social também é contemplada nos princípios da atividade econômica da Constituição Federal de 1988, Art. 170 e seguintes, onde se estabelece a propriedade privada e

\footnotetext{
${ }^{2}$ O Instituto Ethos de Empresas e Responsabilidade Social foi criado em 1998 por empresários e executivos da inciativa privada e é uma organização da sociedade civil de interesse público - Oscip. Tem como missão "mobilizar, sensibilizar e ajudar as empresas a gerir seus negócios de forma socialmente responsável, tornando-as parceiras na construção de uma sociedade justa e sustentável" (ETHOS, s.d.;s.p.). Mais informações em: ETHOS. Disponível em: <http://www3.ethos.org.br/>. Acesso em: 03 dez. 2015.

3 Mais $\quad$ informações: $\quad$ ISO $26000 . \quad$ Disponível <http://www.inmetro.gov.br/qualidade/responsabilidade_social/iso26000.asp>. Acesso em: 18 nov. 2015. Colloquium Socialis, Presidente Prudente, v. 01, n. Especial 2, Jul/Dez, 2017, p.827-832. DOI: 10.5747/cs.2017.v01.nesp2.s0235
} 
sua função social, a defesa do consumidor e do meio ambiente e a redução das desigualdades tanto regionais quanto sociais.

Em pesquisa ao Instituto Ethos, constatamos que suas áreas de fomento e defesa são: Meio Ambiente, defesa para que os governos ajam mundialmente impedindo que o aquecimento global afete de modo profundo a vida no planeta. Direitos Humanos, defesa de ações que proporcionem o enfrentamento a desigualdade social e o empoderamento de grupos discriminados por meio da inclusão do mercado de trabalho. Integridade, defesa da ética nas relações enquanto pilar imprescindível para o desenvolvimento econômico. Gestão Sustentável, geração de muito valor. Economia, inovação no modelo de desenvolvimento para o crescimento, através do fomento e defesa da sustentabilidade. E Apoio aos diversos parceiros com o objetivo de mobilizar, sensibilizar e ajuda-los a gerir seus negócios de forma socialmente responsável, tornando-os responsáveis na construção de uma sociedade responsável e justa.

\section{DISCUSSÕES}

Hoje o Instituto conta com 509 associados, entre empresas, entidades empresariais e instituições de ensino, de diferentes regiões, setores e portes. Conforme dados a seguir:

FIGURA 1 - Porte das Empresas Associadas

\begin{tabular}{|lcc|}
\hline \multicolumn{4}{|c|}{ Atualizado em: 15/O8/17 } \\
Total de empresas associadas: 509 \\
Porte das Empresas Associadas \\
\hline Porte & Total & \% \\
\hline Não Informado & 44 & 8.64 \\
Microempresa & 60 & 11.79 \\
Pequena empresa & 100 & 19.65 \\
Média empresa & 93 & 18.27 \\
Grande Empresa & 212 & 41.65 \\
\hline
\end{tabular}

Fonte: Instituto Ethos.

FIGURA 2 - Empresas Associadas por Estado

\begin{tabular}{|lcclccc|}
\hline \multicolumn{7}{c|}{ Empresas Associadas por Estado } \\
\hline Quantidade & $\%$ & & & \\
AL - Alagoas & 7 & 0.20 & PA - Pará & 4 & 0.79 \\
AP - Amapá & 7 & 0.20 & PB - Paraíba & 7 & 0.20 \\
AM - Amazonas & 3 & 0.59 & PR - Paraná & 20 & 3.93 \\
BA - Bahia & 20 & 3.93 & PE - Pernambuco & 7 & 1.38 \\
CE - Ceará & 7 & 7.38 & PI - Piauí & 7 & 0.20 \\
DF - Distrito Federal & 13 & 2.55 & RJ - Rio de Janeiro & 76 & 14.93 \\
ES - Espírito Santo & 10 & 1.96 & RN - Rio Grande do Norte & 3 & 0.59 \\
CO - Goiás & 15 & 2.95 & RS - Rio Grande do Sul & 12 & 2.36 \\
MA - Maranhão & 7 & 0.20 & SC - Santa Catarina & 17 & 2.16 \\
MT - Mato Grosso & 4 & 0.79 & SP - São Paulo & 254 & 49.90 \\
MS - Mato Grosso do Sul & 3 & 0.59 & SE - Sergipe & 3 & 0.59 \\
MG - Minas Gerais & 36 & 7.07 & TO - Tocantins & 2 & 0.39 \\
& & & Não informado ou no & 7 & 0.20 \\
\hline
\end{tabular}

Fonte: Instituto Ethos.

Para que seja possível monitorar e avaliar a efetivação das atuação e incorporação dos valores de sustentabilidade e da responsabilidade social empresarial (RSE) nas estratégias de negócio de todos os parceiros, o Instituto Ethos desenvolveu uma ferramenta de gestão intitulada 
Indicadores Ethos. A ferramenta permite o autodiagnóstico da gestão para subsidiar os planejamentos e delimitação de metas para o avanço da RSE/Sustentabilidade.

A responsabilidade social, assim, pode variar nas organizações de acordo com as características destas. No entanto, entendemos que o fator motivador da adoção da responsabilidade social vai além da contribuição para a construção de uma sociedade mais justa, da sociabilidade ou da sustentabilidade. A outra face da responsabilidade social, de fato, é permeada de interesses que propiciam uma série de vantagens às empresas, como, por exemplo, o fortalecimento da imagem e da reputação, o diferencial competitivo, a dedução fiscal etc., mas não é nosso objetivo aqui aprofundá-los.

\section{CONCLUSÃO}

O nosso objetivo é, pois, diante o estudo realizado, destacar que a Responsabilidade Social Empresarial está diretamente ligada ao desenvolvimento sustentável, àquele que atende às necessidades do presente sem comprometer a possibilidade das gerações futuras atenderem às suas necessidades.

Portanto, para que se efetive com excelência na prática das organizações, precisa estar atrelada a um processo de gestão (diagnostico, planejamento, execução, monitoramento e avaliação) pautados em princípios éticos e de sustentabilidade, cuja direção não é apenas o hoje, mas os impactos futuros de suas ações.

\section{REFERÊNCIAS BIBLIOGRÁFICAS}

ALESSIO, Rosemeri. Responsabilidade social das empresas no Brasil: reprodução de postura ou novos rumos? Porto Alegre: EDIPUCRS, 2008.

ALESSIO, Rosemeri. Responsabilidade social das empresas no Brasil:

reprodução de posturas ou novos rumos? Revista Virtual Textos \& Contextos, no 2, dez. 2003 . Disponível em:<http://revistaseletronicas.pucrs.br/ojs/index.php/fass/article/viewFile/952/732>. Acesso: 01 jul. 2012.

DRUCKER, Peter Ferdinand. O melhor de Peter Drucker: o homem. Trad. De Maria Lúcia L. Rosa. São Paulo: Nobel, 2001.

ETHOS. Conceitos básicos e indicadores de responsabilidade social empresarial. Rede Ethos de Jornalistas. Versão on-line, São Paulo, junho de 2007, 5ạ ed. Disponível em: $<$ http://www3.ethos.org.br/cedoc/conceitos-basicos-e-indicadores-de-responsabilidade-socialempresarial-5a-edicao-2/\#.VaENWUYd1bs>. Acesso: 11 jul. De 2015.

FISCHER, Rosa Maria. O desafio da colaboração: práticas de responsabilidade social entre empresas e terceiro setor. São Paulo: Editora Gente, 2002.

MACHADO FILHO, Cláudio A. Pinheiro. Responsabilidade social e governança: o debate e as implicações: responsabilidade social, instituições, governança e reputação. São Paulo: Thomson, 2006. $172 \mathrm{p}$.

PAES, A. A Responsabilidade Social Empresarial (RSE): espaço de intervenção profissional do Serviço Social. 2003. Trabalho de Conclusão de Curso. Faculdade de Serviço Social da PUC-SP, São Paulo, 2003. 